\title{
THE ROLE OF INFORMATION TECHNOLOGY AND COMMUNICATION IN ENHANCING THE QUALITY OF THE PERFORMANCE OF HUMAN RESOURCES: A FIELD STUDY AT KING KHALID HOSPITAL IN NAJRAN, SAUDI ARABIA
}

\author{
Abdul Rahman Abdullah Hussein Swan ${ }^{i}$ \\ Administrative Development Researcher, \\ Ministry of Health, \\ Saudi Arabia
}

\begin{abstract}
:
The study aimed to examine the role of information technology and communication in boosting the quality of the performance of human resources at King Khaled Hospital in Najran, Saudi Arabia in the light of variables (information systems and databases, communication systems, information technology in human resources). The descriptiveanalytic approach was used to verify the role of information and communication technology in improving the quality of the performance of human resources. The study sample consisted of (133) employees in King Khalid Hospital in Najran. They responded to a closed-item questionnaire. The results found that there was a statistically significant relationship at the level of significance $(\alpha \leq 0.05)$ between information technology (information systems and databases, communication systems, information technology in human resources) in the quality of the performance of human resources. It also confirmed that there was a statistically significant relationship at the level of significance $(\alpha \leq 0.05)$ for information technology (communication systems, communication techniques) in improving human resource functions. This study recommends that the hospital administration should pay attention to information and communication technology because of its significant impact on the quality of the performance of human resources and its application in all other government agencies and institutions. It is also recommended for the need to keep abreast of technical developments and information technology and work to use them in human resources. In addition, there is a need to develop specialized training programs for human resources staff to work on all programs and use devices to raise the level of performance in a way that benefits the achievement of competitive advantage, excellence, and quality in performance.
\end{abstract}

JEL: D83; J24; I10

i Correspondence: email a.sawaan@gmail.com 
Keywords: information technology, communication, human resources, Saudi Arabia

\section{Introduction}

The world has witnessed many changes at all levels: economic, political, social, or technological. Globalization imposed the free movement of human and material capital and used information technology in business and services sectors without restrictions or conditions until the world became a small village. This, in turn, requires us to assess a lot of services and products offered and their benefits. The sector of health services is very important because it cares about human health. These services must be of a high degree of quality and distinction to form a role model for all health service providers and to obtain a good impression from beneficiaries.

To provide such services, very important strategies must be developed in the development of performance. This requires setting up strategies that care about quality, satisfy the desires of beneficiaries, meet their requirements, and live up to the level of their expectations. The human element is important in providing services and in raising the level of performance in service and production because it achieves the organization's strategies to reach the goals and competitive advantage. This topic is not new. It has been studied before using scientific and statistical methods. Several programs have been applied; some of which succeeded, and some of them were unlucky.

In the light of the widespread use of information and communication technology in all public and private fields, it has become necessary for the human resources department to keep pace with this change and to exploit this method in work and management, especially about data storage, processing, and retrieval. This would help provide very important information at a high speed. So, information and communication technology have a strategic dimension and is considered one of the tools for building educated organizations and a knowledge-based economy. Hospitals in the Kingdom of Saudi Arabia began to keep pace with technological progress to achieve integration between hospitals and the local community. Given the overlap and integration of these several responsibilities, it has become necessary for the departments in all hospitals to switch to digital transformation using technology and the Internet to improve and develop the performance of human resources and carry out their tasks in the required manner. Therefore, there is a deer need to explore the role of information and communication technology in raising the quality of human resources performance at hospitals. This study is significant in that it deals with the importance of raising the performance of human resources and contributes to reaching an understanding of the nature of the relationship between information and communication technology and the quality of human resources performance at King Khalid Hospital in Najran. It also seeks to highlight the desired benefit from the quality of using information and communication technology in improving the quality of human resources performance in King Khalid Hospital in Najran, as a requirement for this sector towards digital transformation in the 
Kingdom of Saudi Arabia's 2030 vision in the health sector. The current study will focus on the most important forms and manifestations of improving the performance of human resources in King Khalid Hospital in Najran. Also, it will investigate the most important factors and reasons that lead to the low quality of information and communication technology used in human resources in King Khalid Hospital in Najran.

\section{Literature Review}

Abdulbari (2003) defined technology as the application of procedures derived from scientific research and practical experiences to solve real problems. Technology here does not mean only tools and devices. Rather, it is the theoretical and practical foundations that aim to improve human performance. As for the procedural definition, it means the scientific applications of science and knowledge in all fields experienced by man in the modern era. It leads to the methods that people use in their inventions and discoveries to meet their needs and satisfy their desires. Since ancient times, man has sought to find the means that help him obtain his livelihood from food and drink. During those ages, man has invented tools, machines, means, and methods that facilitate his work. The term information means facts and organized data that describe a specific situation or problem. Also, some specialists defined it as everything that brings us knowledge and changes our view of things.

Roger Carter defined information technology as the activities and tools used to receive, store, analyze, and communicate information in all its forms, and to apply it to all aspects of our lives including factories, offices, and homes. Alam Al-Din (1990) distinguished information technology in three main aspects namely, the technique of data recording and storage, the technique of data analysis, and the technique of data delivery (communication). Information and communication technology consists of hardware, software, and networks (Sultan, 2000).

Abdulbari (2003) pointed out the importance of information and communication technology. It contributes to obtaining the information required to perform the work distinctively and appropriately. Information and communication technology is used to improve performance to achieve competitive advantage and raise the level of quality of performance. Also, it is used to link individuals and the organization and between different departments within the organization. It reduces the time required to complete work, rationalizes efforts and resources, and removes space and time obstacles. In addition, it allows organizations to achieve very important results in terms of presence in the community and enhancing quality. Further, it contributes to the effectiveness of human resources and raises the level of performance. Finally, it improves productivity and reduces cost.

The management information system (MIS) means that the responsible manager must look at the facility as a group of secondary systems or a series of secondary systems, each of which is an integrated system including inputs, operations, and outputs. For 
example, production introduces raw materials (inputs) and puts them to produce the ready-to-sell commodity (outputs) (Al-Qadi, 1980). The use of management information systems has increased in the last two decades by organizations, whether public or private. Studies have proven that some of these systems succeeded while a number of them failed. This failure is not due to the inappropriate quality of the technology used or the system, but this happened because of other specific factors that were not taken into account.

In this context, Al-Lami (2006) indicated that MIS can fail whenever there is a neglect of the user's psychological reactions and organizational factors by system designers. The standards for developing information systems may differ from one person to another, but there are general features that describe the framework of any successful information system. They are the accuracy and validity of the system, the independence of the system, and its comprehensive use by all beneficiaries. As the presence of these qualities supports the system and raises its quality. Then, a successful information system helps raise the quality of the organization and contributes to the overall quality of management by making its responsibilities on the shoulders of each individual of the organization. The designer, the administrator, the user, and the worker are an important part of the organization because it is linked to the organization's daily activity (Al-Salmi, 1999). The failure of the system means not only stopping it, but also not being used effectively, due to problems in design, costs, data, and operation. As for success, it means to have a high-quality information system that achieves all the objectives and requirements of the beneficiary in a way that covers all work procedures required now and in the future. It also works in a correct technical manner without errors and is easy to maintain and develop, provided that the sum of the material and moral benefits of the system exceeds the sum of the costs. The application of information systems in the organization faces some difficulties as discussed by Sultan (2000). They include the noise of technology and the accompanying unrealistic expectations for the future of technology. Also, it faces difficulty in building, developing, and modifying information systems based on information technology in the administrative field. In addition, it has the difficulty of integrating some systems based on information technology and administrative creativity and predicting the future results of the application of the information system in organizations.

Communication is the communication between the members of an organization and all the internal communications within the organization. It has been defined as a specific process through which information flows and is exchanged within the organization and between the organization and the external environment surrounding it (Al-Salmi, 1999).

Several benefits are realized from the communication process in organizations. Communication between administration and workers contributes to the individual's understanding of the aspects of the work required as well as the goal of his performance of work and the extent of his contribution to achieving the objectives of the organization. Also, it contributes to identifying work problems and obstacles facing the implementers 
of performance, which leads to the search for appropriate methods to overcome them so that the desired goals can be achieved. In addition, it helps create a unity of concept and goal and contributes to reproaching and strengthening the good relations between them, which leads to the strengthening of human relations, raising the morale of workers, and increasing job satisfaction. Furthermore, effective communication eliminates misunderstanding between individuals and groups, thus helping achieve consistency between the various aspects of the activity in the organization. Finally, it is an effective means of management work in the organization and reflects the management's excellence and effectiveness (Al-Salmi, 1999).

There are basic goals in most communication processes in organizations. First, the goal of any communication process is not only to convey information and ideas but rather the goal is persuasion as many leaders in organizations use the communication process to present new ideas to persuade people to follow these ideas. Second, workers are informed of the goals to be implemented, the extent of implementation and obstacles are identified, and the decision-making process is facilitated. Third, the communication process assists management in carrying out its main functions such as plans, policymaking, division of labor, and reconciling the efforts of employees. Also, it provides a positive climate that employees desire to achieve and organize the leadership and direction of human, technical, and financial resources. Finally, it helps link administrative departments with each other and coordinate the access and flow of information to achieve goals (Al-Salmi, 1999).

Effective communication has pillars and principles to be effective. It contains new information and defines the planned goal of the communication process. Also, proficiency in the art of listening because it helps the flow of information and provides an atmosphere of trust between the two parties. In addition, the proper organization of communications within the organization is another pillar of effective communication. So, the administration plays its role in achieving effective communication in the organization. Furthermore, it includes clarity and appropriate timing using the appropriate means, understanding messages objectively, opening channels, and direct communication methods between leaders and workers. Finally, follow-up is another important component through feedback to assess the extent to which the other party can understand the information in a correct manner (Al-Salmi, 1999).

Communication within organizations can be done through some channels. Verbal communication is the communication in which spoken words are used that include words, sentences, or phrases that indicate a useful meaning. Some pictures of this communication are seminars, meetings, interviews, seminars, training programs, and phone calls. In written communication, ideas and information are exchanged using words or symbols and distributed to the employees of the organization. Electronic communications include the Internet, fax, and e-mail. This type of communication enhances the growth and effectiveness of communication between employees. Nonverbal communication is in which facial expressions and body language are used and 
give impressions according to their meaning. For example, the manager may fist his hand and hit the table to confirm the seriousness of the matter. Also, an employee might smile at another because he did a good job.

Communication includes some obstacles. Personal obstacles mean the influences that refer to the sender and receiver in the communication process such as his inability to express well or to choose vague and ambiguous words when communicating due to differences in mental abilities and perceptions because of individual differences. This complicates the communication process and limits its effectiveness (Al-Salmi, 1999). Psychological and social obstacles happen in the event of a weakness in the social relations between workers at their different organizational levels and the failure to raise psychological and social barriers between managers and workers. The importance of creating a friendly and ethical atmosphere between workers and managers helps in improving the communication process in organizations and enhances the chances of achieving goals. Organizational obstacles occur due to the absence of an organizational structure, the widening and large size of the scope of supervision, and a large number of administrative levels. These obstacles negatively affect the correct delivery of information, the absence of clear policies for communication systems within the organization, and the overlap between organizational units. Environmental obstacles include lighting, ventilation, temperature, and noise. All of these obstacles would hinder the effective communication process. Also, the narrow spatial space and a large number of clients impede effective communication and lead to tension during communication (Al-Salmi, 1999).

Given the strength of the relationship between the job of human resources and modern environmental variables in the field of information and communication technology, organizations of all kinds have been prompted to carry out their work efficiently and effectively. Also, they have been promoted to create different methods that focus on improving performance through training as one of the main parameters that aim to keep pace with technical developments and adapt to them. Administrative thought requires reading reality from all directions. The use of information and communication technology in human resources enables it to keep pace with the rapid technological developments in recent times (Touahri, 2015).

The role of information technology in the various functions of human resources is highlighted in the following aspects. Information systems have an effective and significant role in human resource planning because they facilitate the preparation of predictive plans for human resource needs with the assistance of computerized programs that contain statistical characteristics and the development of long, medium, and short plans. Job applications are received through the website or processed and followed up on these requests regularly by following the standards used in employment. They also enable the human resources department to classify the competencies and positions available within the organization. Information systems facilitate recruitment so that it limits favoritism, and the priority of the selection process is for those who meet the 
necessary conditions for work. Also, a distinction is made between applicants utilizing the computer so that there will be no feelings that may affect the selection process and have greater credibility and be accepted by individuals. In addition, it reduces cost and time as it is connected to the organization's database, which helps in rationalizing decisions. Furthermore, it assists in the training process, one of the most important functions of human resources, that aims to make the best use of human capabilities through their development. Information systems allow following the career path in an easy way and without high costs, by entering electronically through the computer to the databases in the organization for working individuals and knowing the capabilities and competencies of each person and the extent of the development of his performance and career progression within the organization. There are specialized programs that help working individuals in determining their career path, judgment, and transitions during the career path. The programs available today help in accelerating the evaluation process and its quality. There are currently specialized programs that calculate wages and assess the performance of individuals in large organizations. The performance of employees is assessed using productivity standards at the desired level of operation, the use of basic data saved in the databases, and the activation of these rules in a complete way. So, the organization can quickly compare the standard performance with the actual performance through the programs used in this field (Touahri, 2015).

There are several advantages of using information technology systems in the human resource job in particular. These systems have helped in rationalizing and controlling the flow of information, which positively affects the competitiveness of the organization and helps it create value. The advantages can be summarized in reducing effort and time, cost control, quality decisions, teamwork, valuing human capital, and workflow (Gouda, 2010).

The communication process is vital in activating human resources. It begins from the moment when the organization adopts the opening of new work positions. This results in the announcement of its desire to attract competencies, whether from within the organization or from outside, through various means of communication. Human resources perform this task through a set of mechanisms that improve their performance. These mechanisms better ensure the performance of the organization and employees (Muhaibel, 2012). The mechanisms include coordination, decision-making, good supervision of workers and good treatment, changing the employees" behaviors, establishing the vulture of organization, and communication and achieving job creativity. The subject of information and communication technology in the performance of human resources has been of interest to researchers for decades. Several previous studies focused on the topic of information and communication technology in the performance of human resources with its various approaches, objectives, importance, hypotheses, methods of analyzing that data, and its relationship to performance.

The study of Ghayat and Karush (2018) aimed to examine the extent of the impact of the use of information and communication technology in improving the performance 
of human resources at the University of Ksadi Merbah, Ouargla, Algeria. The study was based on the descriptive-analytic approach, and a questionnaire was used for collecting information. It was administered to a sample of 80 employees. The data was analyzed using a descriptive analysis program. The study revealed a relationship between the use of information and communication technology and the performance of human resources, which confirmed that the university realized this importance in improving and developing the performance of human resources. There was also a discrepancy in the impact of the use of information and communication technology and the performance of human resources at the university according to the variable of the job category. The study recommended improving the performance of human resources and the optimal use of information and communication technology.

Muhaibel's study (2012) aimed to reveal the benefits that the organization can obtain through information and communication technology in managing its human resources. The researcher relied on the descriptive method. He used observation and interviews as instruments for collecting primary information. One of the most prominent findings of the study was that the applications of electronic management appeared in human resources in receiving vacation requests and other requests from employees and the delivery of information and attached documents to benefit from them. Also, it was shown that the ministry was interested in spreading the culture of accepting change and moving towards e-government in its various forms. The study recommended the need to develop the quality of human resources and the skills of employees in line with the rapid technological and knowledge progress. Also, human resources should take the necessary measures to better restructure human resources according to administrative levels and need to take advantage of the Internet and the internal network in applying the electronic management of human resources to activate their role within the ministry.

Al-Otaibi (2010) examined the impact of the use of information technology on the performance of human resources at the Australian International Academy in Melbourne and its impact on job performance. He also explored the human resources systems currently used in educational institutions and e-educational services systems because of their significant role in the use of technology in human resources management. The researcher used the descriptive-analytic approach to achieve the objectives of the study and used a questionnaire that was distributed to a purposeful sample of (72) employees. It was shown that there was clarity among the study sample of the importance of using information technology in human resource management and their full awareness of its multiple benefits. The academy supported the process of shifting to the use of information technology in human resource management. Also, there was infrastructure at the information technology center in the academy concerned with the study, which was practically sufficient for the transition to the use of information technology in human resource management due to the increased reliance on these technologies significantly in the fields of work. The researcher recommended a formal and practical orientation towards the use of information technology in human resources management and 
providing financial support to information technology centers for their importance in the change process. Also, she recommended keeping pace with the rapid changes in the use of information technology in human resources management and benefiting from electronic educational services in the activities of human resources jobs and adapting internal electronic correspondence instead of paper. This contributes significantly to reducing administrative financial expenses and speeding up work completion.

Touahri (2015) investigated the impact of the use of information and communication technology on the performance of human resources at the Electricity Production Company in Tiaret. The study was based on the descriptive-analytic approach, and a questionnaire was distributed to (189) employees of the electricity company. The study concluded that information and communication technology in the electricity company is a catalyst in developing human resources capabilities and improving their performance. Also, there was a discrepancy in the impact of the use of information and communication technology on the performance of human resources in the company according to the variables of gender and educational level in favor of males and holders of bachelor's degrees. In addition, there was no impact on performance concerning years of experience and job grades. The study recommended that the company should have a future outlook that carries with it some challenges and aspirations in deepening the electronic nature at the level of all departments.

Bouziane and Boubreen (2016) studied the role of internal communication in rationalizing the decisions of a university institution. The researcher used the descriptiveanalytic approach and administrated a questionnaire to collect information from a purposeful sample of (83) participants. The results showed that formal communication was the most common type of communication used in the institution and the higher management focused on effective communication as one of the important elements in the administrative process. Also, the university attached great importance to the communication process in decision-making, and information and communication technology provided great speed and effectiveness in collecting, analyzing, and sending information, which increases the university's ability to rationalize its decisions. The study recommended that the university administration attach great importance to internal communication to increase trust, understanding, and coordination in business and activities. Also, raising the morale of employees and achieving harmony and consistency among them was recommended. More attention to upward communication to enhance the effectiveness of internal communication, which leads to enhancing understanding between employees and managers was suggested.

Khreis (2011) examined the impact of information technology on institutional performance in civil service agencies in Jordan. The study population consisted of all employees of the Ministry of Industry and Trade, and the sample amounted to (173) employees. The study showed the existence of a statistically significant relationship for information technology (hardware components, human resources, software, databases, and networks) in the effectiveness of institutional performance. 
Based on the review of previous studies, it is obvious that most studies have linked information and communication technology to one of the variables and showed a relationship between it and several factors that affect organizations. What distinguishes the current study from previous studies is that it reflects the role of information and communication technology in raising the quality of human resources performance at King Khalid Hospital in Najran. This study is one of the few studies that dealt with this topic at the level of the Kingdom of Saudi Arabia in general and the health sector in particular. This study enriches the topic aspect, which allows researchers to choose one of the variables that fit with the problem of their study to study it in more depth. The previous studies aim to provide the researcher with a comprehensive vision of his research topic and study to help him in formulating the problem and research questions clearly and accurately. The study will try to examine the following research questions:

1) Is there a statistically significant relationship between information and communication technology and the quality of training in human resources?

2) Is there a statistically significant relationship between communication systems and the improvement of human resource jobs?

\section{Material and Methods}

Given the research objectives that the research aims to achieve and after reviewing some previous studies, the researcher applied the descriptive-analytic approach, which is a common approach in the study of phenomena and reality. Also, it is accurate, describes, and defines quantity and quality.

\subsection{Population and Sample of the Study}

The study population consisted of all the employees of King Khalid Hospital in Najran in the Kingdom of Saudi Arabia. The study sample consisted of (150) employees who were randomly selected to respond to the questionnaire statements.

\subsection{Instrument of the Study}

The researcher administered a questionnaire as the main instrument for this study. He prepared the questionnaire after reviewing previous studies and the theoretical framework. It consisted of 21 items divided by three domains: the availability of management information systems and databases in human resources (7 items), the availability of communication systems in human resources (7 items), the extent to which information technology is benefited in human resources ( 7 items). Then, it was sent to the employees and workers of King Khalid Hospital in Najran. The 70 copies of the questionnaire were distributed in person and 51 copies were returned. Nine questionnaires were excluded, so the number of paper questionnaires became 42 . About 91 questionnaires were collected electronically, bringing the total number 133 questionnaires entered into the computer using the statistical program of SPSS. 


\subsection{Validity and Reliability of the Instrument}

The validity of the instrument is the extent to which it measures the purpose for which it was designed. It is the role of information and communication technology in the quality of services and the performance of human resources at King Khalid Hospital in Najran. The instrument of this study was designed to address the quality of human resources performance in the hospital. To be able to achieve this objective, the instrument was designed with the help of studies and periodicals that dealt with the same topic and to reach its final version.

The reliability of the measuring instrument is to give the same results for which the questionnaire was prepared on the sample and in the same conditions. There are different types of methods of measuring reliability, including (Spearman-Brown and Gutman, and Alpha Cronbach). They are a reliability coefficient as shown in Table 1 below:

Table 1: Alpha Cronbach's coefficients and the domains of the study instrument

\begin{tabular}{|l|c|c|c|c|c|}
\hline & & & \multicolumn{2}{|c|}{ Bartlett test } & \\
\hline Domain & $\begin{array}{c}\text { No. of } \\
\text { items }\end{array}$ & $\begin{array}{c}\text { Kaiser's } \\
\text { KMO }\end{array}$ & Value & Sig. & $\begin{array}{c}\text { Alpha } \\
\text { Cronbach }\end{array}$ \\
\hline $\begin{array}{l}\text { Management information systems } \\
\text { and databases in human resources }\end{array}$ & 7 & 0.717 & 169.987 & 0.000 & 0.671 \\
\hline $\begin{array}{l}\text { Communication systems in } \\
\text { human resources }\end{array}$ & 7 & 0.788 & 276.477 & 0.000 & 0.810 \\
\hline Training in human resources & 7 & 0.872 & 412.467 & 0.000 & 0.855 \\
\hline Overall & 21 & 0.870 & 2577.345 & 0.000 & 0.816 \\
\hline
\end{tabular}

Table 3 shows that the various reliability coefficients were higher by more than (60\%). This means that the respondents' answers are reliable and thus give dependence on the results of this study and a possibility for generalizing the results. This result also confirms the safety of study procedures in terms of choosing the appropriate instrument for measurement and application safety.

The internal consistency is calculated by the correlation coefficient between the total score with the questionnaire domains. The correlation coefficient indicated that the items measure something in common, which shows us the validity of the internal construction as shown in Table 2. To find the coefficient of internal consistency, the Pearson correlation coefficient was measured between the total score of each of the study instruments with each of its domains as follows:

Table 2: The values of the correlation coefficients for the domains of the two study instrument

\begin{tabular}{|l|c|}
\hline Domains & Correlation coefficients \\
\hline Management information systems and databases in human resources & $0.716^{* *}$ \\
\hline Communication systems in human resources & $0.805^{* *}$ \\
\hline Training in human resources & $0.832^{* *}$ \\
\hline
\end{tabular}

$\left.{ }^{* *}\right)$ significant at the level of (0.01). 
Table 2 shows that based on the Pearson correlation coefficient for the domains of the study and the total degree of all study domains was positive and at the level of statistical significance (0.01). This means that the domains of the study were consistent with the total degree of study instrument.

The criteria for judging the questionnaire items were based on the five-point Likert scale (strongly disagree (1-1.80=very low), disagree (above 1.80-2.60=low), neutral (above $2.60-3.40=$ medium), agree (above 3.40-4.20=high), strongly agree (above-4.20-5=very high).

\section{Results}

The means and standard deviation of the participants' responses to the questionnaire items were measured as depicted in Table 3.

Table 3: Means and standard deviation of the participants' responses to the questionnaire

\begin{tabular}{|l|c|c|c|}
\hline Item & Means & Standard deviation & Level \\
\hline $\begin{array}{l}\text { Availability of management information systems } \\
\text { and databases in human resources }\end{array}$ & 3.52 & 0.07 & High \\
\hline $\begin{array}{l}\text { Availability of communication systems } \\
\text { in human resources }\end{array}$ & 3.57 & 0.1 & High \\
\hline $\begin{array}{l}\text { The extent to which information technology } \\
\text { is benefited in human resources }\end{array}$ & 3.68 & 1.17 & High \\
\hline
\end{tabular}

It was found that the general average of the domain of the extent to which information technology is benefited in human resources received the highest degree $(M=3.68$, $\mathrm{SD}=1.17)$. This means the respondents' approval for this domain was high. The availability of communication systems in human resources scored second place $(\mathrm{M}=3.57$, $\mathrm{SD}=0.1$ ). This falls within the fourth category of the five-year Likert scale (3.4-4.2), which means that the degree of approval of the sample of the study on the statements of the domain of communication systems in human resources was high. Finally, the domain of the availability of management information systems and databases in human resources amounted to a means of (3.52) and a standard deviation of 0.07. This falls within the fourth category of the five-year Likert scale (3.4-4.2), which means that the degree of approval of the sample members on the statements of the domain of information systems and databases in human resources was high.

Research question 1: Is there a statistically significant relationship between information and communication technology and the quality of training in human resources? 
A FIELD STUDY AT KING KHALID HOSPITAL IN NAJRAN, SAUDI ARABIA

Table 4: Regression and error coefficient for the first research question

\begin{tabular}{|l|c|c|c|c|c|}
\hline Source & Sum of squares & $\mathbf{d f}$ & Means of squares & F & Sig.(-2Tailed) \\
\hline Regression & 33.298 & 3 & \multirow{3}{*}{46.403} & \multirow{2}{*}{$* 0.000$} \\
\hline Error & 50.591 & 170 & 0.179 & & \\
\hline Overall & 83.889 & 173 & & & \\
\hline
\end{tabular}

$\left({ }^{* *}\right)$ significant at the level of $(a=0.05)$.

The $(\mathrm{F})$ value in Table 4 at the significance level of $(\alpha=0.05)$ and the degree of freedom $(3,170)=2.37$.

Table 4 shows the model was valid for testing the research question based on the calculated high value $(F)$ of (46.403), which is higher than its value in the table at the level of significance $(\alpha=0.05)$ and the degree of freedom $(3,170)$. It is clear to us that the variables of information and communication technology and the quality of training in human resources were relatively high, which indicates the statistically significant effect of this variable.

Table 5: Level of significance of $T$ for the first research question

\begin{tabular}{|l|c|c|c|c|c|}
\hline Independent variables & B & Standard deviation & Beta & T & Level of T \\
\hline Information systems & 0.130 & 0.060 & 0.154 & 2.158 & ${ }^{*} 0.032$ \\
\hline Databases & 0.406 & 0.077 & 0.374 & 5.291 & ${ }^{*} 0.000$ \\
\hline $\begin{array}{l}\text { Information technology in } \\
\text { human resources }\end{array}$ & 0.422 & 0.079 & 0.384 & 5.297 & $* 0.000$ \\
\hline
\end{tabular}

$\left({ }^{* *}\right)$ significant at the level of $(\mathrm{a}=0.05)$.

The value of $(\mathrm{T})$ in Table 5 at the level of significance $(\alpha=0.05)=1.96$

It is shown in Table 5 that from the Beta coefficients and T-test that the independent variables (information systems, databases, and information technology in human resources) had an impact on the quality of human resources performance evident in the high Beta coefficients of these variables $(0.154,0.374,0.383)$. Also, there was an increase in the calculated $\mathrm{T}$ value $(2.158,5.291,5.297)$ at a value of 1.96 and a level of significance $(\alpha=0.05)$. This confirms that there was no statistically significant effect at the significance level $(\alpha \leq 0.05)$ for information technology (information systems and databases, communication systems, information technology in human resources) on the quality of training in human resources.

Research question 2: Is there a statistically significant relationship between communication systems and the improvement of human resource jobs?

The regression analysis of variance was used to verify the validity of the model to answer the research question. 
Abdul Rahman Abdullah Hussein Swan

THE ROLE OF INFORMATION TECHNOLOGY AND COMMUNICATION

IN ENHANCING THE QUALITY OF THE PERFORMANCE OF HUMAN RESOURCES:

A FIELD STUDY AT KING KHALID HOSPITAL IN NAJRAN, SAUDI ARABIA

Table 6: Regression and error coefficient for the second research question

\begin{tabular}{|l|c|c|c|c|c|}
\hline Source & Sum of squares & df & Means of squares & F & Sig.(-2Tailed) \\
\hline Regression & 51.634 & 3 & 12.909 & \multirow{2}{*}{66.621} & \multirow{2}{*}{$* 0.000$} \\
\hline Error & 54.641 & 170 & 1.194 & & \\
\hline Overall & 106.275 & 173 & & & \\
\hline
\end{tabular}

$\left({ }^{* *}\right)$ significant at the level of $(a=0.05)$.

The value of $(\mathrm{F})$ in the table at the level of significance $(\alpha=0.05)$ and degree of freedom $(3,170)=2.37$

Table 6 shows that the model was valid for testing the research question based on the calculated high value (F) of (66.621), which is higher than its value in the table (2.37) at the level of significance $(\alpha=0.05)$ and the degree of freedom $(3,170)$. It is clear that the variables of communication systems and improvement of human resource jobs, as this model explains the amount of (49\%) of the variance in the dependent variable of communication systems. This shows that it was relatively high, which indicates the statistically significant effect of this variable.

Table 7: Level of significance of $\mathrm{T}$ for the second research question

\begin{tabular}{|l|c|c|c|c|c|}
\hline Independent variables & B & Standard deviation & Beta & T & Level of T \\
\hline Information systems & 0.130 & 0.060 & 0.154 & 2.158 & ${ }^{*} 0.032$ \\
\hline Databases & 0.406 & 0.077 & 0.374 & 5.291 & ${ }^{*} 0.000$ \\
\hline $\begin{array}{l}\text { Information technology } \\
\text { in human resources }\end{array}$ & 0.422 & 0.079 & 0.384 & 5.297 & ${ }^{*} 0.000$ \\
\hline
\end{tabular}

$\left.{ }^{* *}\right)$ significant at the level of $(\mathrm{a}=0.05)$.

The value of $(\mathrm{T})$ in Table 5 at the level of significance $(\alpha=0.05)=1.96$

The above table shows that the independent variables (information systems, databases, and information technology in human resources) had an impact on the quality of human resources performance in terms of the high beta coefficients of these variables $(0.154,0.374,0.383)$, as well as the high the calculated $\mathrm{T}$ value is $(2.158,5.291,5.297)$ at a value of 1.96 and a level of significance $(\alpha=0.05)$. This confirms that there was no statistically significant effect at the level of significance $(\alpha \leq 0.05)$ for information technology (communication systems, communication techniques) in improving human resource jobs.

\section{Discussion}

This study analyzed the role of information and communication technology in the quality of training in human resources at King Khalid Hospital in Najran. The following are the most important results:

1) The study confirmed that there was a statistically significant relationship between information technology (information systems and databases, communication 
systems, information technology in human resources) in the quality of training in human resources.

2) It also confirmed there was a statistically significant relationship for information technology (communication systems, communication techniques) in improving human resources jobs.

3) It was found that the degree of approval of the study respondents on the items of the domain of benefiting from information technology in human resources at King Khalid Hospital in Najran was high.

4) The degree of approval of the study respondents on the items of the domain of communication systems in human resources at King Khalid Hospital in Najran was high.

5) The degree of approval of the study respondents on the items of the domain of information systems and databases in human resources was high.

The findings of the study are in line with some studies like that of Ghayat and Karush's (2018) that revealed a relationship between the use of information and communication technology and the performance of human resources, which confirmed that the university realized this importance in improving and developing the performance of human resources. It also agrees with that of Touahri's (2015) that concluded that information and communication technology in the electricity company is a catalyst in developing human resources capabilities and improving their performance. In addition, the findings of the study are emphasised by that of Khreis' (2011) that showed the existence of a statistically significant relationship for information technology (hardware components, human resources, software, databases, and networks) in the effectiveness of institutional performance. However, the finding on the role of information technology in improving human resources jobs does not accord with that of Ghayat and Karush's (2018) that showed a discrepancy in the impact of the use of information and communication technology and the performance of human resources at the university according to the variable of the job category.

\section{Recommendations}

Based on the findings of the current study, the study recommends:

- The need for hospital administration to pay attention to information and communication technology because of its significant impact on the quality of training in human resources and its application in all other government agencies and institutions.

- Keeping abreast of technical developments and information technology and working to use them in human resources.

- Developing programs concerned with enhancing the performance of human resources and communication because of their effective role in raising the quality of performance in human resources. 
- Holding specialized training programs for human resources staff to work on all programs and use devices to raise the level of performance in a way that benefits the achievement of competitive advantage, excellence, and quality in performance.

- Working to overcome all the difficulties facing human resources workers to achieve the hospital's goals.

- Enhancing communication between working individuals to raise the level of performance.

- Setting development programs for staff in human resources and hospital staff, in general, to promote the culture of communication and training on modern technology to keep pace with new developments in this field.

- Adopting the concept of knowledge management because it has become one of the modern systems that are concerned with spreading knowledge among employees to enhance performance and improve quality.

\section{Conflict of Interest Statement}

The author declares no conflicts of interests.

\section{About the Author}

Abdul Rahman Abdullah Hussein Swan is an administrative development researcher at Najran Health Directorate at the Ministry of Health in the Kingdom of Saudi Arabia. He holds a master degree in human resources from the College of Business, University of Jeddah. His research interests include the utilization of technology in human resources management.

\section{References}

Abdulbari, I. (2003). Technology of human performance in organizations: theoretical foundations and its implications in the contemporary Arab environment. Cairo: Arab Administrative Development Organization.

Alam Al-Din, M. (1990). Information technology, industry and mass communication. Cairo: Dar Al Arabi for Publishing and Distribution.

Al-Lami, G. O. (2006). Technology management (concepts and approaches to techniques, practical applications). Amman: Curriculum House.

Al-Mughrabi, K. M. (2001). Administration and the general political environment. Amman: Dar Al-Fikr for Culture and Publishing.

Al-Otaibi, A. A. (2010). The impact of the use of information technology on the performance of human resources, a field study on the Australian International Academy. Melbourne: Australian International Academy.

Al-Qadi, A. (1980). Information systems and decision-making in developing countries. Riyadh: Journal of Public Administration. 
Al-Salmi, A. A. (1999). Information systems and artificial intelligence. Amman: Dar Al-Murad for Publishing and Distribution.

Bouziane, A. \& Boubreen, B. (2016). The role of internal communication in rationalizing the decisions of the university institution. Tebessa: Larbi Tebessi University.

Ghayat, K. \& Karush, A. (2018). The effect of using information and communication technology in improving the performance of human resources, a case study of the Ksadi Merbah University of Ouargla. Ouargla: Ksadi Merbah University - Ouargla.

Gouda, M. A. (2010). Human Resource Management. Cairo: Wael Publishing House.

Khreis, N. H. M. (2011). The use of information technology and its impact on performance in civil service agencies in Jordan. Amman: Middle East University.

Muhaibel, M. (2012). Information and communication technology and its role in activating the function of human resources management, a case study of the Directorate of Human Resources at the Ministry of Finance. Algeria: University of Algiers 3.

Sultan, I. (2000). Management information systems, systems entrance. Cairo: University House.

Touahri, F. (2015). The impact of the use of information and communication technology on the performance of human resources in the Algerian institution. Oran: University of Oran 2. 
Abdul Rahman Abdullah Hussein Swan

THE ROLE OF INFORMATION TECHNOLOGY AND COMMUNICATION

IN ENHANCING THE QUALITY OF THE PERFORMANCE OF HUMAN RESOURCES:

A FIELD STUDY AT KING KHALID HOSPITAL IN NAJRAN, SAUDI ARABIA

Creative Commons licensing terms

Authors will retain copyright to their published articles agreeing that a Creative Commons Attribution 4.0 International License (CC BY 4.0) terms will be applied to their work. Under the terms of this license, no permission is required from the author(s) or publisher for members of the community to copy, distribute, transmit or adapt the article content, providing a proper, prominent and unambiguous attribution to the authors in a manner that makes clear that the materials are being reused under permission of a Creative Commons License. Views, opinions and conclusions expressed in this research article are views, opinions and conclusions of the author(s).Open Access Publishing Group and European Journal of Management and Marketing Studies shall not be responsible or answerable for any loss, damage or liability caused in relation to/arising out of conflict of interests, copyright violations and inappropriate or inaccurate use of any kind content related or integrated on the research work. All the published works are meeting the Open Access Publishing requirements and can be freely accessed, shared, modified, distributed and used in educational, commercial and non-commercial purposes under a Creative Commons Attribution 4.0 International License (CC BY 4.0). 